\title{
Black Adolescent Experiences with COVID-19 and Mental Health Services Utilization
}

\author{
Andrae Banks ${ }^{1}$ (D) \\ Received: 2 March 2021 / Revised: 18 April 2021 / Accepted: 19 April 2021 / Published online: 28 April 2021 \\ (C) W. Montague Cobb-NMA Health Institute 2021
}

\begin{abstract}
Background COVID-19 is disproportionately impacting communities of color. Black adolescents are among the most vulnerable to COVID-19, have high mental health service needs, and have low mental health services utilization. During this time of great physical threat due to COVID-19, it is equally important to understand and support the mental health of Black adolescents.

Method This study collected open-ended survey item responses from adolescents (12-17 years old) that identified as Black, living in a city in the Southeastern United States $(n=33)$. Grounded theory was used to analyze the data, revealing details of the lived experience of these Black adolescents during the COVID-19 pandemic.

Results Black adolescents reported that COVID-19 has been both positive and negative for them. Family is of utmost importance to them, as are their peers, whom they do not get to interact with due to changes in the operation of schools. Despite experiencing stress, adaptive responses to COVID-19 are reported. Black adolescents continue to cite issues with mental health services and providers. Financial issues were a common theme for these youth, blocking access to services and causing issues in the home environment.

Conclusions Mental health service providers must address the service access and quality issues repeatedly reported by Black adolescents. Direct action must be taken to facilitate an increase in Black adolescents mental health services utilization and satisfaction. Changes are needed at the individual and macro levels to alter the experience of one of our most vulnerable groups.
\end{abstract}

Keywords Adolescence $\cdot$ Mental health service $\cdot$ COVID

The COVID-19 pandemic has situated itself as public health enemy number one since early 2020. It is disproportionately impacting communities of color across the world, including the United States of America. According to the COVID Tracking Project, individuals that identify ethnically as Black American made up 30 and 34\%, respectively, of COVID-19 cases and deaths, despite representing only $21 \%$ of the population in North Carolina in the year 2020 [1]. As of 2021, the COVID Tracking Project reports that individuals that identify as Black or African American make up 20 and $25 \%$, correspondingly, of COVID-19 cases and deaths [2]. Perhaps due to the overall public health response, inclusive of wearing masks, increased sanitation procedures, the institution of curfews, and the development and administering of vaccines, we observe a decline in the overall cases and deaths

Andrae Banks

abanks19@nccu.edu

1 Department of Social Work, North Carolina Central University, 1801 Fayetteville Street, Durham, NC 27707, USA for Black Americans in North Carolina from 2020 to 2021. However, Black Americans living in North Carolina continue to experience a disproportionately higher rate of death from COVID-19 and is the only ethnic group dealing with this situation compared to White, Hispanic or Latino, Asian alone, Native Hawaiian and Pacific Islander alone, American Indian or Alaskan Native alone, those identifying as two or more ethnicities, and those that were some other ethnicity alone. This disparate burden in North Carolina reflects similarly to the burden experienced by Black populations in other states as well [3].

Social workers and public health professionals must use a lens of social and economic determinants of health to competently attend to the complex needs of the most vulnerable individuals in our communities [4]. Black Americans are the ethnic group that often suffers as the most vulnerable in our society [3]. Children and youth, such as adolescents, may also be counted among the most vulnerable [5, 6]. Black American youth may be of particular risk in the current times and may require increased attention to monitor, support, and improve their health and well-being. While we are striving to 
understand the implications of COVID-19 on the physical health of our communities, it is important to also consider the implications on the mental health of those most impacted.

\section{Literature Review}

Adolescents suffer from high rates of mental illness [7, 8], lower mental health service utilization, and less control over their socioeconomic environment $[9,10]$. Poverty is a key contributor to lower mental health service utilization for all ages and ethnicities [9]. The literature documents that Black adolescents, in particular, have high mental health service needs [11,12], despite much less service utilization [13, 14]. Black adolescents are less likely to seek help via formal services [10]. This already subpar developmental context may be exacerbated by COVID-19 and warrants investigation to help support already vulnerable Black adolescents.

Currently, there is a dearth of literature focused on the impact of COVID-19 on adolescents and their mental health broadly. This scarcity extends to a lack of research on Black adolescents and their mental health during the COVID-19 pandemic. One study did examine the impact of COVID-19 on adolescents ages 13-16 and their mental health, longitudinally [15]. This study found that adolescents experienced elevated levels of depression and anxiety and a decrease in life satisfaction after government restrictions due to COVID-19 and the transition to online education. Adhering to the stayat-home orders and social connectivity was protective against reduced mental health. The adjustments created by COVID19 do seem to take a toll on adolescents in this context [15]. However, this study was based in New South Wales, Australia, and $82 \%$ of the sample identified as White, while $79 \%$ of the sample reported middle to high socioeconomic status.

Another study detailed the experience of Hispanic and/or Latinx youth ages 10-14 in the United States [16]. The findings suggested that Hispanic and/or Latinx youth that experienced higher amounts of mental health issues prior to the pandemic also experienced a decline in symptoms during the pandemic. These reductions were experienced uniquely in the category of externalizing problems for Hispanic and/or Latinx youth, in addition to internalizing and total problem reduction as well. This study did include a small sample of youth with other ethnicities, including Black youth that made up 9-10\% of the sample [16]. Black youth also experienced lower issues with internalizing and total problems but did not experience any decline in attention or externalizing issues. There is need to further investigate the impacts of the COVID19 pandemic on youth within the United States context, youth from lower socioeconomic status, and across ethnicities, including Black adolescents.

\section{Mental Health Service Utilization}

Recognized barriers to Black adolescent mental health services utilization include a different understanding of mental health issues between caretakers of Black adolescents and providers [17-19], a lack of trust in mental health service providers by Black adolescents and adults [17, 19-21], a lack of perceived need for service [17, 18, 22], and low belief in the efficacy of treatment [20,21]. Privacy apprehensions [21-24], service distance from adolescent neighborhoods [23], transportation, scheduling, and childcare issues [18], and high stigma $[18,21]$ also limit mental health services utilization $[20$, $22,25]$.

Many of these barriers carry undertones of a history of discrimination and socioeconomic disparity experienced by Black Americans. In a context that is already full of barriers and limited access, COVID-19 is likely to exacerbate existing challenges for Black American adolescents optimal mental health. This study was conducted to explore the impact of the COVID-19 pandemic upon Black adolescent experiences with mental health and mental health services utilization.

\section{Research Questions}

In order to advance more understanding of the impact of COVID-19 on Black adolescent mental health services utilization, a survey was used to investigate the following research questions: (a) How has COVID-19 been positive or negative on your life?; (b) If there has been COVID-19 exposure in the immediate family, what happened and how has it made you feel?; (c) What barriers exist for the adolescent to starting mental health services of any kind?; (d) What would help you get the mental health services you want?; (e) What would support you in having the best mental health possible?; and (f) What important topics or ideas do you think social work researchers should try to ask people about our study in the future related to mental health, mental health services, and social work?

\section{Method}

The data used in this analysis was sampled from adolescents that identify as Black in an urban community in Central North Carolina. The final analytical sample contained 33 respondents, aged 12-17 years (mean age of 14.97), and included 15 females and 18 males. This study used a purposive convenience sample, focused on homogeneous sampling of Black adolescents ages 12-17 living in specific locations. The average annual parental income of this sample was $\$ 33,575.00$. Fifteen percent of families reported zero income, and $24 \%$ of families reported an income below the 2021 Federal Poverty 
Guidelines established value of $\$ 26,500.00$ for a family of four [26]. Only $27 \%$ of families reported income above $\$ 40,000.00$ per year. Recruitment was conducted via community partners specializing in programs or services for Black youth and/or mental health in addition to local churches. Some community partners provided youth that experience mental health issues, although this was not a requirement to participate in the study. Additional details of these community partners are being withheld in order to help ensure the anonymity of study participants.

After caregiver consent and adolescent assent, participants were administered a survey delivered electronically in combination with telephone communication with researcher. All of the survey items were delivered electronically. Researcher used telephone follow-up if a participant provided a response that needed clarification for the researcher or left an item blank. All responses were recorded electronically. Any additional information collected by researcher via telephone was entered into the dataset. This procedure was utilized in order to minimize health risk exposures due to COVID-19. Participants received $\$ 20$ gift cards as remuneration. Information was provided on how to connect with local mental health services. The university's Institutional Review Board approved this study.

\section{Analysis Plan}

\section{Qualitative Analysis}

This study used grounded theory to explore open-ended responses to the research questions. Grounded theory is a methodology that provides flexibility and structure, enabling researchers to explore phenomena that are less understood [27]. The research process for grounded theory is built upon the interaction of various processes including purposive sampling, data collection, coding, memos, and comparative analysis. There were three levels of coding used, including initial, intermediate, and advanced. The initial coding took the original participant responses and assigned a description of each phenomenon that was observed within the data from the perspective of the researcher. In intermediate coding, categories or themes were established from the initial codes and reflecting iteratively on the data to capture interconnected higher-level phenomena.

In the advanced stage of coding, the categories were woven into a storyline through which the theory would emerge. Memos of the researcher's thoughts were kept as well throughout the entire process. This was done in part to produce materials for a paper trail and to document what changes were made in the coding process and the rationale supporting those changes. This entire process transforms the data into a cohesive story of the experiences of the participants. This method allows for rigor to be established in qualitative research, built upon the researcher's knowledge base, fit with the research question, and proper execution of the method [27].

\section{Member Checking}

The researcher engaged in member checking with participants. The researcher contacted multiple participants via telephone to attempt the member checking. Eight participants were available for the follow-up and were given summaries of the results. These participants agreed that the findings were accurate overall. When asked if there were any additional insights they would like to provide, the participants reassured the researcher that the current information was sufficient and that there was no additional information to collect.

\section{Results}

\section{COVID-19's Impact on Adolescent Life}

There were three main categories generated for the impact of COVID-19 in general, including social connections, stress, and stress response. Most of the challenges mentioned by adolescents due to COVID-19 centered around their friends and family, as can be expected for this age group. Unique identifiers have been added to each participant's quote, but the names have been changed from actual names to protect anonymity. Here are examples of participant responses:

a) 'It's been negative because I can't go to school and see my friends." Star, 12 years old, female.

b) "I hate it and I'm mad that it took me out of my high school, took me away from my life as I know it with my friends and school.” Derrick, 16 years old, male.

Friends appear to be very important, and schools still appear to be the main environment for fostering those connections.

Beyond friends, Black adolescents were also greatly concerned with their families during this experience of COVID19. Examples of what participants shared about their families include:

a) "It has made me realize how much I love having the freedom to do things even if I don't want to do it. Spending more time with family." Joshua, 14 years old, male.

b) "Worrying about your health and that of your family." Ashley, 13 years old, female. 
Given the concerns with family and missing out on school, stress was a theme that consistently emerged. Specific examples of Black adolescent expressions of stress included:

a) "Always in fear of getting the virus." Carter, 15 years old, male.

b) "It put some pressure on me psychologically." Robert, 16 years old, male.

However, Black adolescents showed great resiliency and some positive stress responses. Responses that demonstrated this include:

a) "Results of COVID-19 has made me think more about my health and nutrition." Sean, 15 years old, male.

b) "I say positive because I think I'm more driven to start a business." Jasmine, 15 years old, female.

\section{COVID-19 Exposure in the Family}

For those Black adolescents that experienced someone in their immediate family contracting COVID-19, the responses were categorized as family, stress, and financial concerns. Tatiana, who is a 15-year-old female, expressed that her parents and grandmother experienced COVID-19: "Both of my parents \& my grandma had COVID-19. I was worried, scared, and tired. There was a lot of hospital visits. My parents weren't working so I was worried about food \& the rent getting paid. It impacted my mom's mental health really bad. She was not herself at all. I seen my grandma in a very emotional state. It was just hard."

Frank, a 16-year-old male, reported an experience with his father:

"Well, my father got it, but he doesn't live with us, and he has recovered. I was scared at the time though."

\section{Barriers to Mental Health Services}

When it comes to barriers to mental health service utilization, the categories that emerged were fear of COVID-19, provider concerns, lack of need for service, and financial issues. Examples of each category, respectively, include:

a) "COVID is messing a lot of stuff up and I'd rather not be around people that may have it." Gary, 14 years old, male.

b) "Some MH Providers are in to the business for the $\$$ and not the general care and concern of the individual." Felicia, 15 years old, female.

c) "I'm sure my parents don't have the extra money for it." Teresa, 14 years old, female.
There is need for multidimensional work to help Black adolescents utilize mental health services at increasing rates.

\section{Supports for Mental Health}

When it comes to Black adolescents' beliefs about what supports mental health, family support, knowledge of mental health service connection, quality providers, and financial resources are the key themes. The same is true of their beliefs for accessing mental health services. Family support is consistently found to be important for Black adolescents in overall mental health and connecting to services, as one participant provided some context for:

"Find website or tell your parents or friend what are good mental health services." Abby, 14 years old, female.

Apollo, a 15 years old male, echoed the sentiment of family as well:

"continued open communication with parents."

Many Black adolescents expressed concerns with providers, as evidenced by these responses:

a) "The right match for me." Ricky, 16 years old, male.

b) "More professionals that understand teenage boys." Dillon, 16 years old, male.

Black adolescents repeatedly offered responses that indicated finances were a key factor in improving mental health:

a) "Provide free service or cheaper / Maybe a little price decrease." Edward, 15 years old, male.

b) "Provide best for low price." Barry, 16 years old, male.

\section{Adolescent-Guided Future Studies}

When asked about what social work and mental health researchers should focus on in future studies, Black adolescents shared a variety of thoughts. Some examples include:

a) The relationship between finances and their mental health, stated as "Financial help and what it does to mental health." Jasmine, 15 years old, female.

b) Self-esteem and self-efficacy, stated as "How do teenage boys value themselves self worth, self motivation?" Dillon, 16 years old, male.

c) To be asked more about themself in general, stated as "Ask more about them." Manny, 16 years old, male.

It appears as though some Black adolescents may be more open to talking with mental health professionals and/or researchers but are looking to be engaged in different dynamics than what has been offered previously. 


\section{Discussion}

\section{COVID-19's Impact on Adolescent Life}

COVID-19 changed Black adolescents quality of life in both positive and negative ways. Overall, Black adolescents showed resilience and adapted to COVID-19-induced changes positively. Some of the positive changes included becoming more health conscious and being more reflective of different aspects of life including hygiene and entrepreneurship. In this way, COVID-19 served as a catalyst for self-improvement. However, some Black adolescents struggled with being out of school physically, with observations of family hardships, and with separation from peers. Additional supports may benefit Black adolescents that are having a more challenging time adjusting to the new social environment.

Supports should focus on the family and school environments and aim at fostering and maintaining social connections with peers. Clinicians engaging with Black adolescents should pay attention to how Black adolescents have lost or made connections with family, peers, and others, acute stressors in their lived experience, and how these youth are adapting to the stressors. Prior research with adolescents has found that separation from caregivers, such as when fathers experience incarceration, correlates with reduced mental health outcomes [28]. COVID-19 could be a cause of separation from caregivers both temporarily and long term, taking a negative toll on Black adolescent health in a cumulative manner given the disproportionate experience of Black male incarceration. This study also begins to examine household assets and debts and the relationships those factors have with adolescent mental health outcomes [28]. Increasing assets and debts (within limits) for families, respectively, are protective against poorer mental health outcomes for adolescents. These findings further highlight the family environment as critical to any work performed to protect and improve the lives of Black adolescents.

Social workers and other professionals should help reduce maladaptive behaviors, but there may be some value in also reinforcing adaptive behaviors. Peer connections may be a suitable approach to reinforcing positive behaviors in youth and creating natural supports for mental health. Helping youth create new social connections, maintain prior social connections, and engage in productive activities are strategies to mitigate some of the negative circumstances of COVID-19. Finding ways to build upon and enhance Black adolescent interests, including health behaviors and entrepreneurial or asset-building activities, within the more traditional array of services may be beneficial to boosting overall health in a cumulative fashion.

\section{COVID-19's Impact on Family}

When a family member contracted COVID-19, the experience was more acutely permeated by a focus on family, intense levels of fear and stress, and financial concerns. Black adolescents with familial COVID-19 experience may need more attention and supports to cope with this disease's impact. Black families tend to provide more social supports to their families across social, emotional, and mental health domains [14, 29-32]. So, during this time, when family members are ill and access to other family members is more limited, special consideration should be given to Black adolescents.

Service providers should aim to reduce stress and support the family, especially with basic needs like food and shelter. Without basic needs being met, Black adolescents are less likely to positively engage with mental health treatment providers and services. Providers may need to assist youth with alternative methods of maintaining social connections, supporting their caregivers, and scheduling follow-up sessions to reevaluate service provision once COVID-19 is not an immediate issue for families. Caregivers and relatives may also be in need of mental health services after dealing with COVID-19. Clinicians should expand their assessments and attempt to collect critical information about additional family members, possibly beyond the nuclear family, to examine if additional supports and services may be needed within the support system of the adolescents coming into service.

\section{Barriers and Supports to Mental Health}

\section{COVID-19 as Barrier to Mental Health}

An additional barrier of great concern was COVID-19 itself. Some Black adolescents expressed fear and anxiety about leaving their homes to go anywhere, including treatment spaces. Given the real chance of COVID-19 being a part of our everyday lives for the next few years or even permanently, this will be an important piece of information to consider as we work to increase and improve mental health service connections. It also provides some support for the continued expansion of telehealth services while individuals are most comfortable at home. For Black adolescents, COVID-19 adds to a long list of barriers to mental health service connection, and providers must work to reduce or eliminate the additional obstacle to overall health and well-being for these youth.

\section{Financial Resources}

The most noteworthy individual barrier for Black adolescents to mental health services is a lack of financial resources. From an inability to budget for mental health service fees to a lack of a computer or Internet service, Black adolescents have concrete barriers to accessing services. Family-level factors in adverse contexts, such as mental health services that fail to address issues stemming from the socioeconomic context of adolescents and their families, affect mental health treatment utilization $[23,33]$. There is continued need for direct work to 
be done to alleviate the barriers to mental health services through a lens of the social determinants of health for Black adolescents.

These findings have straightforward implications in the manners through which mental health services access and quality improvement must proceed. The field must focus on the social determinants of health, specifically the financial circumstances of individuals and families to promote increased service access and quality. These efforts must ensue in direct services, supportive services, and policy advocacy for changes at local, state, and national levels that will actually level the field for historically and presently disadvantaged groups, such as Black Americans.

The impact of financial resources has been heavily documented in relation to mental health needs in the literature. Experiencing a consistent pattern of lower financial resources is a major risk factor for increased stress-related psychopathology, lower quality of life, and impeded social adjustment for adolescents across measures [23, 33-35]. Black Americans and their families disproportionately experience socioeconomic inequality [5, 6, 9, 36-39]. Black adolescents suffer from a lack of financial, social, and human capital accumulation in the United States that feeds into intergenerational poverty [6]. Unless the helping professions support the correction of this social and historical context for Black adolescents and their families, findings such as the ones in this study will not change for the betterment of Black adolescents mental health or well-being.

Work centered on specific, actionable changes to mental health policies and procedures to increase access and quality for vulnerable populations is needed. A few ideas of what can be piloted and tested include giving/loaning of computers to facilitate telehealth services, charging reduced fees, fee subsidization, and/or group therapy rates specialized for families that are lower than current group therapy rates. Another idea that could be tested is some form of payment to Black adolescents for engaging consistently with mental health services. This payment could be some direct benefit (cash, gift card, books, etc.) or an indirect benefit (a free session after a specified number of sessions, a coupon to a local shop of interest to the youth, or a contribution to a college fund or some other asset-building measure).

Mental health interventions targeted to Black families can improve the uptake of mental health services for Black adolescents [14], so a financial benefit embedded within mental health services may have utility. Financial boosts have been shown to positively influence academic achievement in ethnic minority adolescents [40-42] and may be beneficially applied in a mental health services utilization context. At a macro level, policy could be developed that rewards adolescents and their families for participating in mental health treatment on some kind of consistent basis, e.g., once a year akin to physicals with medical providers. Maybe this could be linked to some kind of tax break or another financially oriented benefit for families.

\section{Perceptions of Providers}

Beyond the financial barriers, the other major concern for Black adolescents is with their perceptions of providers. Consistent with prior literature, youth expressed distrust of providers [17, 19-21], feeling like providers did not care about them $[18,21]$, and that the quality of services was lacking [20,21]. Black adolescents also want providers that match them culturally. Increased utilization of mental health services that cater to racial/ethnic and/or sex differences, use a strengths-based perspective, and have a stress-reduction focus may improve outcomes for adolescents [20, 22, 43]. Increasing the number of ethnically/culturally matched providers, increasing the quality of providers, increasing the quality of treatments, improving accessibility to services, and finding ways to blend standardized services with more genuine connections to the patients and their families are all strategies to improving Black adolescent mental health and mental health service utilization.

One idea toward this effort could involve funding education and training for individuals who are of Black ethnicity, who are interested in being a licensed therapist, and who want to focus on Black populations. Another idea to improve service quality is linking profits, bonuses, and benefits for providers to patient progress and satisfaction measures. If providers benefit more when their patients' overall health improves and satisfaction with services reaches and maintains at high levels, we may see more concentrated investment on improvement in these areas. Ideas like this have the potential to produce benefits for everyone involved.

\section{Lack of Perceived Need for Mental Health Service}

A final idea that emerged from the data was not accessing services because Black adolescents perceived no need for services. Some Black adolescents are healthy, well-adjusted individuals that are truly functioning well. This is not often the story that is told, but one that could provide great value if examined. The field of social work could benefit from learning about Black adolescents that have thrived and continue to do so. This may reveal factors that could be isolated, developed, and targeted toward Black youth that are not as resilient as some other Black youth. Examinations of what drives the resiliency and higher levels of health at the individual, family, community, and system levels may be of extreme value.

There could be a possibility that Black adolescents are denying the need for services for some other reasons beyond just not perceiving a need. It is also possible that the stigma against mental health providers or lack of suitable providers drives the wedge between Black adolescents and any thoughts of 
receiving services. Black adolescents view mental health treatment as a final option and benefit from social supports that attempt to address issues and encourage mental health services utilization [44, 45]. Given what this data has revealed, it could be that mental health services are not perceived as accessible anyway, so Black adolescents might deny the need to connect to them.

The strong and positive relationships among Black adolescents and their families may function as a protective factor, but there is a possibility that this dynamic could also be exacerbating mental health service connections for Black adolescents. Black adolescents may be denying the need for services as a way of supporting their caregivers, who some Black adolescents know may not be able to pay for those services. Black American adults, especially males, often suffer from John Henryism and the avoidance of proper care due to financial strain [4]. An investigation into how Black adolescents may relate to this concept is warranted. Studies are needed to separate out the effects of financial considerations, personal sensitivities, and how these may shape relationships to mental health providers, the mental health system, and mental health overall.

\section{Adolescent-Guided Future Studies}

Black adolescents report that there is a need for more social work research focused on the relationship between finances and their mental health. This provides further insight into a dynamic that is well-understood in the literature for adults but requires more attention within the context of adolescent development. Furthermore, adolescents are acutely aware of financial circumstances, how it shapes their lives, and the ways intervening in that space would improve their experiences. Black adolescents also expressed a desire to be asked about their health, feelings, coping skills, self-esteem, and selfefficacy by social work researchers. It seems that Black adolescents are ready for increased attention and have something to communicate about their experiences.

Perhaps, a participatory action research method could be used to carry out some of this future work. There is a need for more integrated care programs, developed with direct input from the Black adolescents these programs will serve. An example of this type of program is called "allcove," which is the first of its kind implemented in the United States [46]. This program provides access to mental health services, school support, and online connections to support adolescent mental health and well-being. Adolescents have a direct say in the programming by participating in the Youth Advisory Group [46].

Providing Black adolescents with opportunities to influence their mental health services experiences, connect with other youth, and help guide future research seems promising as an approach to reducing mental health stigma, increasing mental health services utilization, and improving the overall health and well-being of this unique group. Additionally, finding ways to either alleviate the burden of costs or facilitate the accumulation of resources is likely to increase the chances of success in promoting increased health for Black adolescents.

This study has some limitations that must be noted. The sample included 33 Black adolescents living in a specific location and may not be reflective of all Black American adolescents across the state of North Carolina or beyond. Although the study lacks generalizability due to the purposive sampling technique employed, it still contributes to an understanding of Black adolescent mental health during the COVID-19 pandemic and insights into further research on this population.

\section{Conclusion}

Given the unique circumstances surrounding the COVID-19 pandemic that disproportionately impacts people of color and Black adolescent vulnerability, high mental health service needs, and low mental health service utilization, it is important to understand how Black adolescents are coping with their life circumstances. This study has revealed that Black adolescents are experiencing tremendous stress at this time but are also responding in resilient ways that deserve more attention. These adaptive responses are prompting continued inquiry into how to increase mental health service utilization and into the factors that can bolster youth outside of the clinical settings. Within clinical settings, providers must heed the message that some youth continue to be unaware of service options and service access and quality are consistent issues that must be directly addressed in order to serve this population fairly.

Peers matter for Black adolescents and efforts must be made to create and maintain social connectivity for youth, despite the COVID-19 pandemic. The Black family is still the linchpin to Black adolescent mental health, although a focus on improving the financial circumstances of the Black family is emerging as more cogent in the alleviation of Black adolescent suffering. Finding ways to directly and indirectly promote financial well-being for Black adolescents and their families is of utmost importance to eliminating mental health disparities experienced by Black American populations. Black adolescents seem to have a voice. That voice wants to express their thoughts, feelings, hopes, and dreams. More attention needs to be given to their voice by researchers and practitioners, in order to promote healthier experiences for them and all in this society. As we listen more to and invest resources into Black adolescents, we are sure to find the best ways to improve the lives of some of the most vulnerable in our society. 
Supplementary Information The online version contains supplementary material available at https://doi.org/10.1007/s40615-021-01049-w.

Acknowledgements The author would like to thank the study participants for their contributions to this work.

Code Availability Not applicable

Funding This research was funded by a grant from the Julius L. Chambers Biomedical Biotechnology Research Institute Advanced Center for COVID-19 Related Disparities.

Data Availability Not applicable

\section{Declarations}

Ethics Approval The North Carolina Central University Institutional Review Board approved this study.

Consent to Participate Caregiver informed consent and adolescent assent were both obtained prior to study enrollment.

Consent for Publication Caregiver informed consent and adolescent assent for publication were both obtained prior to study enrollment.

Conflict of Interest The author declares no competing interests.

\section{References}

1. The Covid Tracking Project. (2020). Retrieved from https:// covidtracking.com/race/dashboard\#state-nc

2. The Covid Tracking Project. (2021). Retrieved from https:// covidtracking.com/race/dashboard\#state-nc

3. Laurencin C, McClinton A. The COVID-19 pandemic: a call to action to identify and address racial and ethnic disparities. $\mathrm{J}$ Racial Ethn Health Disparities. 2020;7:398-402. https://doi.org/ 10.1007/s40615-020-00756-0.

4. Hudson D, Banks A, Holland D., Sewell W (2019). Understanding health inequalities experienced by Black men. In D.M. Griffith, M.A. Bruce, \& R.J. Thorpe (Eds.), Men's health equity: A handbook (1st ed., pp. 408-432). Routledge. https://doi.org/10.4324/ 9781315167428

5. McLoyd V, Aikens N, Burton L. Childhood poverty, policy, and practice. In: Damon W, Lerner R, Renninger KA, Sigel I, editors. Handbook of child psychology: Child psychology in practice. Thousand Oaks, CA: Sage; 2006. p. 700-75.

6. Page M, Conger K, Guyer A, Hastings P, Thompson R. Children and the intergenerational transmission of poverty: research frontiers and policy implications: Center for Poverty Research; 2016.

7. Centers for Disease Control and Prevention (2017). Fatal injury reports, national and regional, 1999 - 2014. Retrieved from Web site: https://webappa.cdc.gov/sasweb/ncipc/dataRestriction_inj. html

8. Centers for Disease Control and Prevention. Mental health surveillance among children - United States, 2005-2011. Morb Mortal Wkly Rep. 2013;62(2):1-35.

9. Chow JC, Jaffee K, Snowden L. Racial/ethnic disparities in the use of mental health services in poverty areas. Am J Public Health. 2003;93(5):792-7. https://doi.org/10.2105/AJPH.93.5.792.

10. Scott LD, McMillen JC, Snowden LR. Informal and formal help seeking among older Black male foster care youth and alumni. J
Child Fam Stud. 2015;24:264-77. https://doi.org/10.1007/s10826013-9832-0.

11. Byck GR, Bolland J, Dick D, Ashbeck AW, Mustanski BS. Prevalence of mental health disorders among low-income African American adolescents. Soc Psychiatry Psychiatr Epidemiol. 2013;48:1555-67. https://doi.org/10.1007/s00127-013-0657-3.

12. Lau M, Lin H, Flores G. Racial/ethnic disparities in health and health care among U.S. adolescents. Health Research and Educational Trust. 2012;47(5):2031-59. https://doi.org/10.1111/j. 1475-6773.2012.01394.x.

13. Alegria M, Green JG, McLaughlin KA, Loder S (2015). Disparities in child and adolescent mental health and mental health services in the US. William T. Grant Foundation Inequality Paper, 1-23. https://wtgrantfoundation.org/library/uploads/2015/09/Disparitiesin-Child-and-Adolescent-Mental-Health.pdf

14. Breland-Noble AM, Bell C, Nicolas G. Family first: the development of an evidence-based family intervention for increasing participation in psychiatric clinical care and research in depressed African American adolescents. Fam Process. 2006;45(2):153-69. https://doi.org/10.1111/j.1545-5300.2006.00088.x.

15. Magson NR, Freeman JYA, Rapee RM, Richardson CE, Oar EL, Fardouly J. Risk and protective factors for prospective changes in adolescent mental health during the COVID-19 pandemic. Journal of Youth and Adolescence. 2021;50:44-57. https://doi.org/10. 1007/s10964-020-01332-9.

16. Penner F, Hernandez Ortiz J, Sharp C. Change in youth mental health during the COVID-19 pandemic in a majority Hispanic/ Latinx US sample. Journal of the American Academy of Child and Adolescent Psychiatry. 2021;60(4):513-23. https://doi.org/10. 1016/j.jaac.2020.12.027.

17. Campbell RD, Long LA. Culture as a social determinant of mental and behavioral health: a look at culturally shaped beliefs and their impact on help-seeking behaviors and service use patterns of Black Americans with depression. Best Pract Ment Health. 2014;10(2): 48-62.

18. Lindsey MA, Chambers K, Pohle C, Beall P, Lucksted A. Understanding the behavioral determinants of mental health service use by urban, under-resourced Black youth: adolescent and caregiver perspectives. J Child Fam Stud. 2013;22:107-21. https://doi. org/10.1007/s10826-012-9668-z.

19. Walton JR, Mautone JA, Nissley-Tsiopinis J, Blum NJ, Power TJ. Correlates of treatment engagement in an ADHD primary carebased intervention for urban families. J Behav Health Serv Res. 2014;41(4):539-47. https://doi.org/10.1007/s11414-013-9385-4.

20. Copeland VC. Disparities in mental health service utilization among low-income African American adolescents: closing the gap by enhancing practitioner's competence. Child Adolesc Soc Work J. 2006;23(4):407-31. https://doi.org/10.1007/s10560-0060061-x.

21. Samuel IA. Utilization of mental health services among AfricanAmerican male adolescents released from juvenile detention: examining reasons for within-group disparities in help-seeking behaviors. Child Adolesc Soc Work J. 2015;32:33-43. https://doi.org/ 10.1007/s10560-014-0357-1.

22. Hall CA, Sandberg JG. "We shall overcome": a qualitative exploratory study of the experiences of African Americans who overcame barriers to engage in family therapy. Am J Fam Ther. 2012;40:44558. https://doi.org/10.1080/01926187.2011.637486.

23. Dashiff C, Dimicco W, Myers B, Sheppard K. Poverty and adolescent mental health. Journal of Child and Adolescent Psychiatric Nursing. 2009;22(1):23-32. https://doi.org/10.1111/j.1744-6171. 2008.00166.x.

24. Thompson R, Dancy BL, Wiley TRA, Najdowski CJ, Perry SP, Wallis J, et al. African American families' expectations and intentions for mental health services. Adm Policy Ment Health Ment 
Health Serv Res. 2012;40:371-83. https://doi.org/10.1007/s10488012-0429-5.

25. Cummings JR, Druss BG. Racial/ethnic differences in mental health service use among adolescents with major depression. J Am Acad Child Adolesc Psychiatry. 2011;50(2):160-70. https:// doi.org/10.1016/j.jaac.2010.11.004.

26. Poverty guidelines for the 48 contiguous states and the District of Columbia. (2021). Retrieved from https://www.federalregister.gov/ documents/2021/02/01/2021-01969/annual-update-of-the-hhspoverty-guidelines

27. Tie CT, Birks M, Francis K. Grounded theory research: a design framework for novice researchers. Sage Open Medicine. 2019;7:18. https://doi.org/10.1177/2050312118822927.

28. Banks A, Fields L. Correlates of incarceration of fathers, socioeconomic influences, and mental illness. Social Work in Public Health. 2020;36:1-12. https://doi.org/10.1080/19371918.2020.1851842.

29. Cabrera NJ, Ryan RM, Mitchell SJ, Shannon JD, Tamis-LeMonda CS. Low-income, nonresident father involvement with their toddlers: variation by fathers' race and ethnicity. J Fam Psychol. 2008;22(4):643-7. https://doi.org/10.1007/s12111-001-1016-0.

30. Jones J, Mosher, W.D. Fathers' involvement with their children: United States. National health statistics reports; no 71. Hyattesville, MD: National Center for Health Statistics; 2006-2010. p. 2013.

31. Leavall AS, Tamis-Lemonda CS, Ruble DN, Zoshuls KM, Cabrera NJ. African American, White and Latino fathers' activities with their sons and daughters in early childhood. Sex Roles. 2012;66: 53-65. https://doi.org/10.1007/s11199-011-0080-8.

32. Tandon DS, Solomon BS. Risk and protective factors for depressive symptoms in urban African American adolescents. Youth Soc. 2008;41(1):80-99. https://doi.org/10.1177/0044118X08327520.

33. Gladstone TRG, Beardslee WR, O'Connor EE. The prevention of adolescent depression. Psychiatr Clin N Am. 2011;34(1):35-52. https://doi.org/10.1016/j.psc.2010.11.015.

34. McLaughlin KA, Breslau J, Green JG, Lakoma MD, et al. Childhood socio-economic status and the onset, persistence, and severity of DSM-IV mental disorders in a US national sample. Soc Sci Med. 2011;73:1088-96. https://doi.org/10.1016/j. socscimed.2011.06.011.

35. Reiss F. Socioeconomic inequalities and mental health problems in children and adolescents: a systematic review. Soc Sci Med. 2013;90:24-31. https://doi.org/10.1016/j.socscimed.2013.04.026.

36. Boshara R, Emmons WR, Noeth BJ (2015). The demographics of wealth: How age, education and race separate thrivers from strugglers in today's economy. Federal Reserve Bank of St. Louis, 1-24. https://www.stlouisfed.org/ /media/files/pdfs/hfs/essays/hfs-essay3-2015-age-birth-year-wealth.pdf

37. DeNavas-Walt C, Proctor BD, U.S. Census Bureau, Current Population Reports, P60-252, Income and Poverty in the United States: 2014, U.S. Government Printing Office, Washington, DC, 2015.

38. Domhoff, G.W. (2013). Wealth, income, and power. Retrieved from http://whorulesamerica.net/power/wealth.html

39. Oliver DAH, Brody GH. The health status of children and adolescents. In R. L. Braithwaite et al. (Eds.), Health Issues in the Black Community (pp. 35-53). John Wiley \& Sons, Inc;(2009).

40. Beale Spencer M, Noll E, Cassidy E. Monetary incentives in support of academic achievement: results of a randomized field trial involving high-achieving, low-resource, ethnically diverse urban adolescents. Eval Rev. 2005;29(3):199-222. https://doi.org/10. 1177/0193841X04273329.

41. Williams Shanks TR. The impacts of household wealth on child development. J Poverty. 2007;11(2):93-116. https://doi.org/10. 1300/J134v11n02_05.

42. Zhan M, Sherraden M. Assets and liabilities, race/ethnicity, and children's college education. Child Youth Serv Rev. 2011;33(11): 2168-75. https://doi.org/10.1016/j.childyouth.2011.06.024.

43. Terzian M, Hamilton K, Ericson S (2011). What works to prevent or reduce internalizing problems or socio-emotional difficulties in adolescents: lessons from experimental evaluations of social interventions. Child Trends Fact Sheet. https://childtrendsciw49tixgw5lbab.stackpathdns.com/wp-content/uploads/2013/06/ 2011-34DUPWhatWorksSocio-Emotional.pdf

44. Lindsey MA, Joe S, Nebbitt V. Family matters: the role of mental health stigma and social support on depressive symptoms and subsequent help seeking among African American boys. The Journal of Black Psychology. 2010;36(4):458-82. https://doi.org/10.1177/ 0095798409355796.

45. Lindsey MA, Korr WS, Broitman M, Bone L, Green A, Leaf PJ. Help-seeking behaviors and depression among African American adolescent boys. Soc Work. 2006;51(1):49-58. https://doi.org/10. 1093/sw/51.1.49.

46. Stanford University Department of Psychiatry and Behavioral Sciences (2021). allcove. Retrieved from Web site: https://med. stanford.edu/psychiatry/special-initiatives/allcove.html

Publisher's Note Springer Nature remains neutral with regard to jurisdictional claims in published maps and institutional affiliations. 